\title{
Characteristics of COPD Patients Enrolled into Rehabilitation Programme in Copenhagen
}

\author{
Ramune Jacobsen, ${ }^{1}$ Ea Rusch, ${ }^{2}$ Anne Frølich, ${ }^{3}$ Per Kragh Andersen, ${ }^{2}$ and Nina Godftredsen ${ }^{4}$ \\ ${ }^{1}$ Institute of Preventive Medicine, Frederiksberg Hospital, Nordre Fasanvej 57, Hovedvejen 5, 1st Floor, \\ 2000 Frederiksberg, Denmark \\ ${ }^{2}$ Section of Biostatistics, Department of Public Heath, Faculty of Health and Medical Sciences, University of Copenhagen, \\ Øster Farimagsgade 5B, 1040 Copenhagen, Denmark \\ ${ }^{3}$ Department of Integrated Health Care, Bispebjerg Hospital, Bispebjerg Bakke 23, 2400 Copenhagen, Denmark \\ ${ }^{4}$ Department of Pulmonary Medicine, Bispebjerg Hospital, Bispebjerg Bakke 23, 2400 Copenhagen, Denmark \\ Correspondence should be addressed to Ramune Jacobsen; ramune.jacobsen@regionh.dk
}

Received 25 November 2012; Accepted 11 December 2012

Academic Editors: A. Celi, C. Flores, A. S. Melani, and K. Nishimura

Copyright (c) 2013 Ramune Jacobsen et al. This is an open access article distributed under the Creative Commons Attribution License, which permits unrestricted use, distribution, and reproduction in any medium, provided the original work is properly cited.

Pulmonary rehabilitation (PR) is a recommended standard of care for patients with chronic obstructive pulmonary disease (COPD), as it improves exercise capacity and health-related quality of life (HRQOL), attenuates perceived dyspnoea, and decreases the need for hospitalisation. The objective of this study was to compare medical and sociodemographic characteristics of COPD patients who were enrolled and completed the PR with those of COPD patients who were resident in the same municipality but were not enrolled into this PR. The data used for comparison came from the Danish National Registers. The COPD patients who were enrolled and completed the rehabilitation differed from COPD patients who were not enrolled into the rehabilitation in the following: (1) there were more women than men among those who were enrolled; (2) those who were enrolled had higher socioeconomic status compared to those who were not enrolled; and (3) those who were enrolled into the rehabilitation used more COPD-specific medication compared to those who were not enrolled. In conclusion, to enrol more COPD patients into PR, special attention needs to be paid to COPD patients from lower socioeconomic status groups as well as male patients.

\section{Introduction}

Chronic obstructive pulmonary disease (COPD) is a disease that clinically manifests itself by gradual physical impairment, increasing breathlessness, and episodes of acute exacerbations which deteriorate overall health and require hospitalisation. Morbidity and mortality related to COPD is increasing [1]. COPD is especially frequent in Denmark. According to the calculations done by the Copenhagen City Heart Study in 2010, an overall prevalence of COPD in Denmark was $17.4 \%$ among individuals of 35 years of age or older, while estimated COPD prevalence from studies in other developed countries ranged from $5 \%$ to $19 \%$ with the majority being in the vicinity of 10\% [2]. In the Capital Region of Denmark, the prevalence of COPD among individuals older than 40 years old of age is $15 \%$ corresponding to 120,000 citizens. Among those, more than 19,000 meet the criteria for a rehabilitation programme, that is, forced expiratory volume during one second (FEV1) being less than $80 \%$ of predicted value, and dyspnea scoring 3 or higher on the Medical Research Council (MRC) scale [3].

Pulmonary rehabilitation (PR) is a recommended standard of care for patients with COPD. According to the definitions set by the American Thoracic Society and the European Respiratory Society, comprehensive PR programmes should include patient assessment, exercise training, education, and smoking cessation, as well as psychosocial support $[4,5]$. Studies show that PR improves exercise capacity and health-related quality of life (HRQOL), attenuates perceived dyspnoea, and decreases the need for hospitalisation [6]. On the other hand, according to a recent Danish study, only a small proportion of COPD patients gets to experience the PR offer [7]. 
The Integrated Rehabilitation Programme for Chronic Conditions project (SIKS) implemented rehabilitation programmes for people with four chronic conditions, including COPD, in one of the districts in the municipality of Copenhagen. The programme was described in detail elsewhere $[8,9]$. In brief, PR was provided in the municipality's health care centre and in the ambulatory of the local hospital. Patients with severe or very severe COPD (i.e., FEV1 lower than $50 \%$ of predicted) were referred to PR in the outpatient pulmonary department of the local hospital; patients with moderate COPD (i.e., FEV1 between 50\% and $80 \%$ of predicted) and residing or having their general practitioner (GP) in the local area were referred to rehabilitation at the municipality's health care centre. The programme offered included educational and physical training sessions, augmented by dietician consultation and smoking cessation. The entire programme lasted for three months and resulted in statistically significantly improved values in COPD patients' exercise capacity, dyspnoea, and disease-specific as well as general HRQOL, and lastly it prevented future increase in health care utilisation. The multivariable analysis of the magnitude of the PR effects showed that the patients who at baseline had the most impaired health status benefitted the most from the program [10].

The objective of the present study was to compare diseasespecific and sociodemographic characteristics of the COPD patients who were enrolled and completed rehabilitation during the SIKS project with those of the COPD patient population who lived in the same municipality, but were not enrolled in the SIKS.

\section{Methods}

2.1. Patients. Data from the two following patient groups were analysed: (1) rehabilitation group of 118 COPD patients; these patients were referred and completed their rehabilitation in the SIKS project during the years 2005-2007; Civil Registration Numbers (CRNs) of these patients were received from the institution (i.e., the health care centre or the local hospital) where the rehabilitation took place and (2) comparison group COPD patients; these patients were selected from the National Patient Register, selection criteria being residence of the municipality of Copenhagen, COPD diagnosis in the years 2005-2007, older than 35 years old of age, and not being enrolled in the SIKS, which means that they were either not referred to rehabilitation or, if referred, never showed up. A COPD diagnosis in our case was defined as having contact with Danish hospital system (hospitalisation, outpatients, or emergency visit) during a defined period of time with the action diagnosis J44.X in the International Classification of Diseases version 10 (ICD 10), used in Denmark since 1994. The aforementioned group of patients consisted of 3474 individuals.

2.2. Data Analysis. Using the patients CRN, several Danish National Administrative Registers were used to obtain the individual data of the patients in the two groups. Sociodemographic data and information on COPD medication dispensed, along with information on utilisation of general medical practice services, were obtained from the registers maintained by Danish Statistics. Hospital health care utilisation data were obtained from the National Patient Register which is maintained by the National Board of Health. Health care utilisation data for the rehabilitation group patients were taken from two calendar years before the year when the rehabilitation started, that is, from 2003-2004, 20042005, or 2005-2006, depending on the rehabilitation start date for the relevant person. Sociodemographic data for the rehabilitation group were used from the year prior to the year when the rehabilitation started, that is, from 2004, 2005 , or 2006, depending on the start date of rehabilitation for the relevant person. For the comparison group patients, utilisation data from 2004-2005 were used. The reason for choosing data from 2004-2005 was that the health care utilisation numbers (i.e., numerical variables) all rose over time. Hence we chose data from 2004-2005, as this was the midpoint. Sociodemographic data for this group from 2005 was used. All the data were merged on individual level on Danish Statistics server, and the access to data was provided after Danish Statistics replaced CRN with anonymous identification number. The Danish Data Protection Agency gave permission for data retrieval and analyses.

To assess the differences in sociodemographic and medical characteristics, the patient groups' characteristics were compared using the following tests: (1) numerical variables were tested by $t$-tests; all numerical outcomes, but age, were not normally distributed; therefore, logarithmically transformed data $\log (x+1)$ were used in $t$-tests and $(2)$ categorical outcomes were tested by chi-square tests. SAS version 9.2 was used for data validation and analyses.

\section{Results}

The population of COPD patients who were enrolled and completed the rehabilitation programme differed from COPD patients who were not enrolled it in the following ways: (1) there were statistically significantly more women than men among those who were enrolled; (2) there were statistically significantly more wealthy patients among those who were enrolled; (3) there were statistically significantly more persons with high school/higher education degrees among those who were enrolled; and (4) the summary dispensed defined daily dose (DDD) of COPD medications was statistically significantly higher among those who were enrolled. Age, the number of COPD-specific emergency, and outpatient visits during a two-year period did not differ significantly between the two patient groups. The number of COPD-specific hospitalisations as well as the number of bed days in a two-year period had a tendency to be larger in the group of patients who were not enrolled into PR (see Tables 1 and 2).

\section{Discussion}

The development and local implementation of the rehabilitation programme described lasted from April 2005 to September 2007. In 2010, when implementing the Disease Management Programme (DMP) for COPD in the Capital 
TABLE 1: Medical characteristics of COPD patients from different groups.

\begin{tabular}{|c|c|c|c|}
\hline Outcome & $\begin{array}{l}\text { Rehabilitation } \\
\text { group } \\
(n=118)\end{array}$ & $\begin{array}{l}\text { Comparison } \\
\text { group } \\
(n=3474)\end{array}$ & $P$ value \\
\hline $\begin{array}{l}\text { COPD emergency visits, } \\
\text { median ( } 5 \% \text { percentile; } \\
95 \% \text { percentile) }\end{array}$ & $0(0 ; 3)$ & $0(0 ; 2)$ & 0.48 \\
\hline $\begin{array}{l}\text { COPD hospitalisations*, } \\
\text { median ( } 5 \% \text { percentile; } \\
\text { 95\% percentile) }\end{array}$ & $0(0 ; 5)$ & $0(0 ; 2)$ & 0.14 \\
\hline $\begin{array}{l}\text { COPD bed days }{ }^{* *} \text {, median } \\
\text { ( } 5 \% \text { percentile; } 95 \% \\
\text { percentile) }\end{array}$ & $0(0 ; 18)$ & $0(0 ; 15)$ & 0.14 \\
\hline $\begin{array}{l}\text { COPD outpatient visits, } \\
\text { median ( } 5 \% \text { percentile; } \\
95 \% \text { percentile) }\end{array}$ & $0(0 ; 15)$ & $0(0 ; 8)$ & 0.53 \\
\hline $\begin{array}{l}\text { GP visits }{ }^{* * *},(5 \% \\
\text { percentile; } 95 \% \text { percentile })\end{array}$ & $21.5(4 ; 60)$ & $22(4 ; 64)$ & 0.90 \\
\hline $\begin{array}{l}\text { COPD medicine summary } \\
\text { DDD, ( } 5 \% \text { percentile; } 95 \% \\
\text { percentile) }\end{array}$ & $743(0 ; 3703)$ & $480(0 ; 3515)$ & 0.0002 \\
\hline
\end{tabular}

Region of Denmark, already implemented rehabilitation programme became a part of this DMP. The existing evidence shows that it is important, both clinically and economically, to target DMPs for those patients of the most urgent needs [10]. Therefore, the purpose of this study was to compare the disease-specific and sociodemographic characteristics of the COPD patients who were enrolled into the rehabilitation as a part of DMP with those of COPD patients living in the same municipality who were not enrolled into PR. If the compared characteristics were similar, it could be suggested that the enrolment into rehabilitation was equal for all COPD patients. If the characteristics were different, it could be hypothesised that the rehabilitation enrolment was unequal and only some patients were being enrolled. If so, the description of the characteristics of patients enrolled if compared to those who were not enrolled could show in which direction rehabilitation enrolment should be aligned.

In the present study, disease-specific characteristics were assessed using health care utilisation outcomes chosen for two reasons. Firstly, hospitalisation frequency is linearly correlated with COPD disease severity stages assessed using spirometric testing [3]. Secondly, health care utilisation data, contrary to clinical measures or spirometry test results, are easily available from the Danish National Patient Register. Our analyses showed that health care utilisation outcomes did not differ significantly between the two patient groups, suggesting that the COPD disease severity was approximately equal between the patients who were and were not enrolled into PR.

In contrast, sociodemographic characteristics of the COPD patients who were and were not enrolled in the
TABLE 2: Sociodemographic characteristics of COPD patients from different group.

\begin{tabular}{|c|c|c|c|}
\hline Outcome & $\begin{array}{c}\text { Rehabilitation } \\
\text { group } \\
(n=118)\end{array}$ & $\begin{array}{c}\text { Comparison } \\
\text { group } \\
(n=3474)\end{array}$ & $P$ value \\
\hline Age $^{*}$, mean $(\mathrm{SD})$ & $70.5(8.8)$ & $70.0(12.4)$ & 0.56 \\
\hline \multicolumn{4}{|l|}{ Gender, percentage } \\
\hline Male & 31.4 & 41.5 & \multirow{2}{*}{0.03} \\
\hline Female & 68.6 & 58.5 & \\
\hline \multicolumn{4}{|l|}{ Income ${ }^{* *}$, percentage } \\
\hline First quartile & 21.2 & 25.1 & \multirow{4}{*}{0.10} \\
\hline Second quartile & 17.8 & 25.2 & \\
\hline Third quartile & 29.7 & 24.8 & \\
\hline Fourth quartile & 31.4 & 24.9 & \\
\hline \multicolumn{4}{|l|}{ Wealth $^{* * *}$, percentage } \\
\hline First quartile & 21.2 & 25.1 & \multirow{4}{*}{0.002} \\
\hline Second quartile & 18.6 & 25.2 & \\
\hline Third quartile & 20.3 & 25.2 & \\
\hline Fourth quartile & 39.8 & 24.5 & \\
\hline \multicolumn{4}{|l|}{ Ethnicity, percentage } \\
\hline Danish & 94.9 & 91.7 & \multirow{2}{*}{0.21} \\
\hline Immigrant/descendent & 5.1 & 8.3 & \\
\hline \multicolumn{4}{|l|}{ Civil status, percentage } \\
\hline Single & 63.3 & 69.1 & \multirow{2}{*}{0.20} \\
\hline Married/partnership & 36.4 & 30.9 & \\
\hline \multicolumn{4}{|l|}{ Employment, percentage } \\
\hline Working & 10.2 & 12.0 & \multirow{3}{*}{0.55} \\
\hline Retired & 89.0 & 81.9 & \\
\hline Outside the workforce & 0.9 & 6.1 & \\
\hline \multicolumn{4}{|l|}{ Education, percentage } \\
\hline Primary/vocational & 76.3 & 75.5 & \multirow{3}{*}{$<0.0001$} \\
\hline $\begin{array}{l}\text { High school/higher } \\
\text { education }\end{array}$ & 22.0 & 9.9 & \\
\hline Not specified & 1.7 & 14.6 & \\
\hline
\end{tabular}

$n$ : sample size; SD: standard deviation.

${ }^{*}$ For rehabilitation group in a year when rehabilitation took place, for comparison group in 2005; ${ }^{* *}$ personal net income per month; ${ }^{* * *}$ personal net economical values, like real estate, capital, shares, and so forth.

Notes: (1) quartiles were calculated on the basis of the data from the entire sample: $118+3474=3592$; (2) for employment and education, variables have been combined to make the chi-square tests valid: for employment, retired tested against not retired; for education, high school/higher education tested against not high school/higher education.

rehabilitation were statistically significantly different. For instance, there were more males among those who were not enrolled into the rehabilitation. Possibly, the fact that males were underrepresented in the rehabilitated patient group can partly be explained by the lack of motivation among men. This is in agreement with the results of earlier conducted studies claiming that those who participate in health interventions are more motivated to take care of their health [11]. It also could be possible to hypothesise that men 
could not afford to leave their jobs for rehabilitation activities, but knowing that the majority of patients in both groups were in the age of retirement and that men and women are equally employed in Denmark, this would be an unlikely explanation. Furthermore, our results showed that the COPD patients enrolled into the rehabilitation were wealthier and better educated compared to the comparison group patients. Generally, education and wealth is associated with income [12]. According to the statistics of the municipality of Copenhagen from the years 2005-2007, the district where the rehabilitation programme took place did not differ significantly from the remaining districts in terms of percentages of households in different income groups [13]. Therefore, we cannot say that the district where the rehabilitation took place was populated with mostly educated and wealthy people, and, therefore, more of such people were enrolled into PR.

Consequently, the two analysed patient groups were different with regard to their socioeconomic status position (SEP) in a way so that those with higher SEP were more likely to enrol into the rehabilitation programme. This situation highlights the importance of social determinants in health and health care. Generally, social determinants are important for multiple aspects in almost every disease [14]. Regarding COPD, it was shown that mortality from COPD was associated with the level of education. In men, it was also associated with employment status, household income level, housing conditions, and cohabitation status [15]. COPD hospitalisation frequency, however, was associated with education and income in both men and women [16]. The importance of social determinants for COPD patients' participation in rehabilitation programmes has not yet been determined. Thus, our study is novel in this respect. Furthermore, our findings can be interpreted in the light of the health services utilisation model developed by Andersen [17]. This model suggests three possible mechanisms creating social differences in health services use: (1) differences in medical need across SEP groups, (2) differences in health and illness behaviour across SEP groups, and (3) differences in access to health services across SEP groups. Thus, following the model, COPD patients with higher SEP were more often enrolled into PR because they (1) could have worse health, (2) could behave differently responding to their health problems, and/or (3) could have better access to rehabilitation services if compared to those in lower SEP. As discussed earlier, disease progression was similar in the two analysed patients groups; thus, different morbidity does not seem to be the most convincing explanation behind the differences in enrolment into PR between the patients with different SEP in our case. Differences in access to rehabilitation do not seem to fully explain why those with the lower SEP were less often enrolled into PR in our case either. The arguments for the latter are the following. Health care in Denmark is financed by the Government and municipalities and is free of charge for direct users, so financial concerns should not restrict enrolment into PR. The majority of the patients in both groups were retired, so job duties should not restrict enrolment into rehabilitation either. Finally, the programme was provided in the city downtown area with a good available public transport network suggesting that transportation problems should not have significant influence on access too. Consequently, different health and illness behaviour might be the most reasonable explanation behind the differences in rehabilitation enrolment between different SEP groups' patients. Patients in the lower SEP could for instance not have been in contact with their GP regarding their disease, or the outpatient pulmonary department, as often as those in the higher SEP, therefore, could not be getting referrals to rehabilitation, or they could not be ever showing up for rehabilitation even if they were referred. If so, health professionals need to develop special strategies to target and motivate COPD patients in the lower SEP so that they enrol into available rehabilitation programmes afforded to them.

The study has several limitations. Firstly, the methodological shortcoming is that in order to indirectly assess COPD disease severity level, the summary DDD of COPDspecific medication was calculated. Such an approach might not be the optimal way to address morbidity. Partly, because of periodical fluctuation in the manner people discharge their prescriptions, medicine compliance problems, and the absence of the method validation studies. Indeed, the question of COPD medication should be investigated more closely. Secondly, only a limited number of COPD patients in Copenhagen could receive the previously described rehabilitation offer in 2005-2007, as the programme at the time was provided only in one district of the municipality. To confirm our findings, analogical studies from more recent years, when PR programmes as a part of DMP for COPD were implemented in other districts in Copenhagen as well, should be warranted.

\section{Conclusion}

Not all COPD patients in need of rehabilitation and living in the municipality of Copenhagen take advantage of this potentially health improving treatment. To enrol more patients into PR, special attention needs to be paid to COPD patients from lower socioeconomic status groups as well as male patients.

\section{Acknowledgments}

The study is a part of the Danish DISMEVAL, which is a European Commission project, Grant Agreement no. 223277. The study is also cosponsored by the University of Copenhagen.

\section{References}

[1] WHO, "World Health Report 2000," http://www.who.int/ whr/2000/en/.

[2] P. Fabricius, A. Løkke, J. L. Marott, J. Vestbo, and P. Lange, "Prevalence of COPD in Copenhagen," Respiratory Medicine, vol. 105, no. 3, pp. 410-417, 2011.

[3] P. Lange, J. L. Marott, M. Dahl, T. S. Ingebrigtsen, J. Vestbo, and B. G. Nordestgaard, "Substantial need for early diagnosis, rehabilitation and treatment of chronic obstructive pulmonary disease," Danish Medical Journal, vol. 59, no. 4, Article ID A4396, 2012.

[4] L. Nici, C. Donner, E. Wouters et al., "American thoracic society/European respiratory society statement on pulmonary 
rehabilitation," American Journal of Respiratory and Critical Care Medicine, vol. 173, no. 12, pp. 1390-1413, 2006.

[5] A. L. Ries, G. S. Bauldoff, B. W. Carlin et al., "Pulmonary rehabilitation: joint ACCP/AACVPR evidence-based clinical practice guidelines," Chest, vol. 131, no. 5, pp. 4S-42S, 2007.

[6] Y. Lacasse, R. Goldstein, T. J. Lasserson, and S. Martin, "Pulmonary rehabilitation for chronic obstructive pulmonary disease," Cochrane Database of Systematic Reviews, no. 4, Article ID CD003793, 2006.

[7] B. Bjoernshave, J. Korsgaard, C. Jensen, and N. C. Vinther, "Participation in pulmonary rehabilitation in routine clinical practice," The Clinical Respiratory Journal, vol. 5, no. 4, pp. 235-244, 2011.

[8] E. Borg, J. Egsgaard, A. Frølich et al., Sammenhængende Indsats for Kronisk Syge. Evaluering af et samarbejdsprojekt mellem Bispebjerg Hospital, Sundheds- og Omsorgsforvaltningen, Københavns Kommune og praktiserende læger på Østerbro, Klinisk Enhed for Sygdomsforebyggelse, Bispebjerg Hospital, Region Hovedstaden \& Sundheds- og Omsorgsforvaltningen, Københavns Kommune, København, 2008.

[9] A. Frolich, D. Host, H. Schnor et al., "Integration of healthcare rehabilitation in chronic conditions," International Journal of Integrated Care, vol. 10, Article ID e1033, 2010.

[10] R. Jacobsen, A. Frolich, and N. S. Godtfredsen, "Impact of exercise capacity on dyspnea and health-related quality of life in patients with chronic obstructive pulmonary disease," Journal of Cardiopulmonary Rehabilitation and Prevention, vol. 32, no. 2, pp. 92-100, 2012.

[11] A. H. Davis, "Exercise adherence in patients with chronic obstructive pulmonary disease: an exploration of motivation and goals," Rehabilitation Nursing, vol. 32, no. 3, pp. 104-110, 2007.

[12] E. Lahelma, P. Martikainen, M. Laaksonen, and A. Aittomäki, "Pathways between socioeconomic determinants of health," Journal of Epidemiology and Community Health, vol. 58, no. 4, pp. 327-332, 2004.

[13] K. Kommune, "Hustande efter hustandstype og indkomst," http://www.kk.dk/statistik.

[14] WHO, Closing the Gap in A Generation. Health Equity through Action on the social Determinants of Health, World Health Organization, Geneva, Switzerland, 2008.

[15] E. Prescott, N. Godtfredsen, J. Vestbo, and M. Osler, "Social position and mortality from respiratory diseases in males and females," European Respiratory Journal, vol. 21, no. 5, pp. 821-826, 2003.

[16] E. Prescott, P. Lange, and J. Vestbo, "Socioeconomic status, lung function and admission to hospital for COPD: results from the Copenhagen City Heart Study," European Respiratory Journal, vol. 13, no. 5, pp. 1109-1114, 1999.

[17] R. M. Andersen, "Revisiting the behavioral model and access to medical care: does it matter?" Journal of Health and Social Behavior, vol. 36, no. 1, pp. 1-10, 1995. 


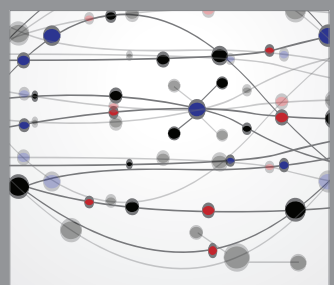

The Scientific World Journal
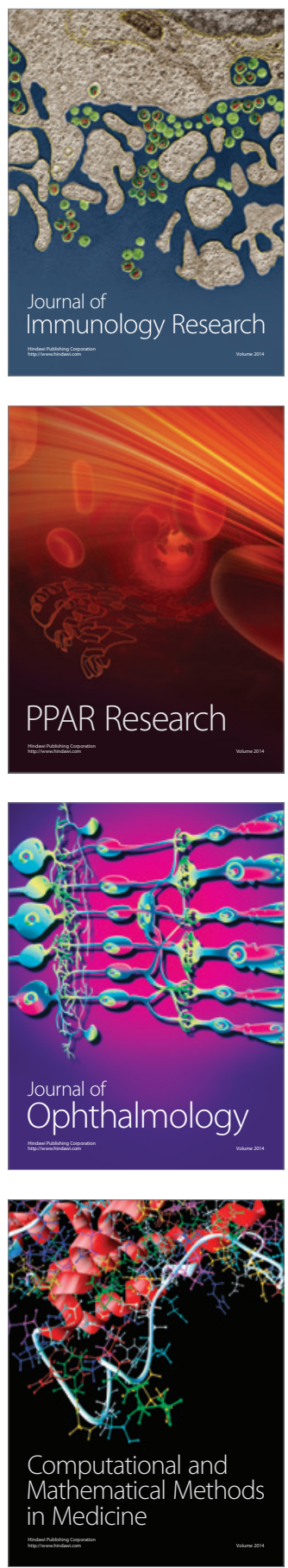

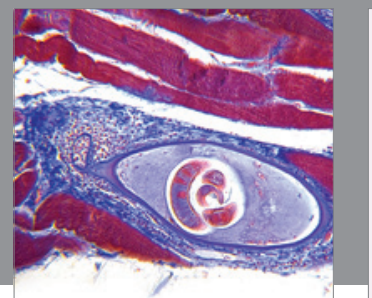

Gastroenterology

Research and Practice
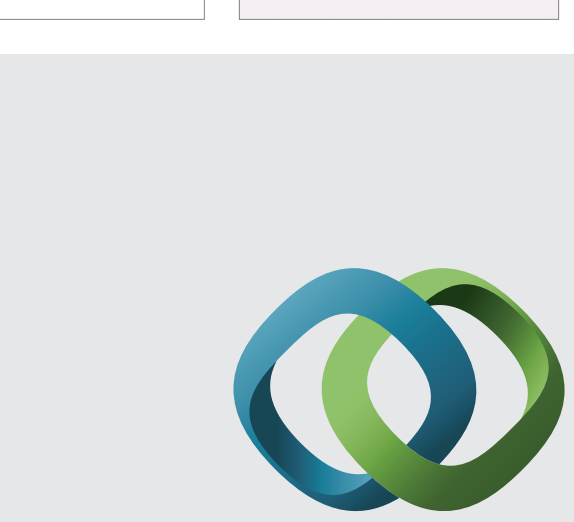

\section{Hindawi}

Submit your manuscripts at

http://www.hindawi.com
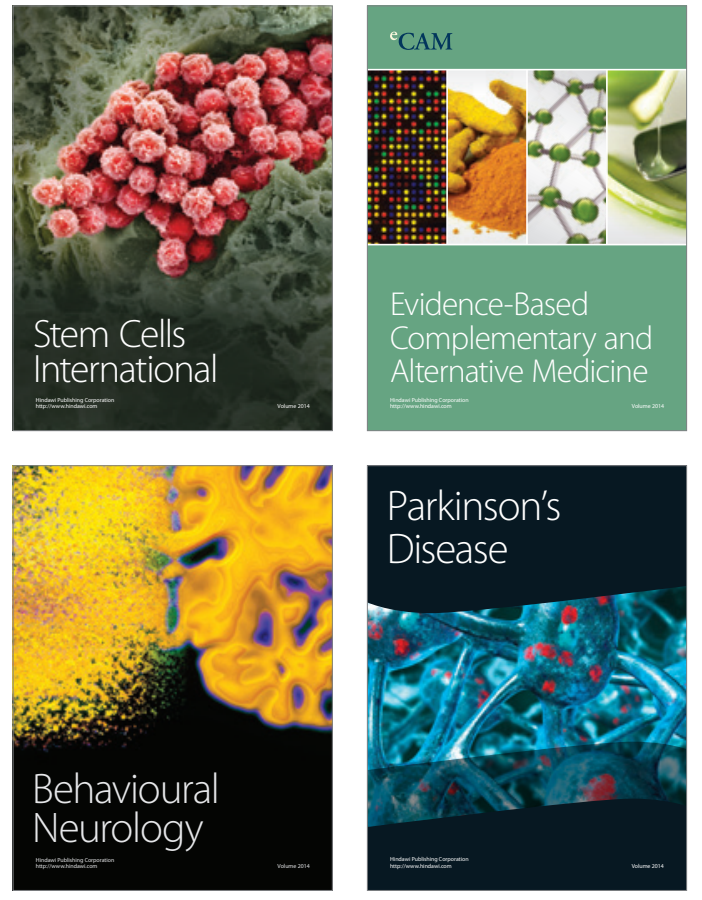
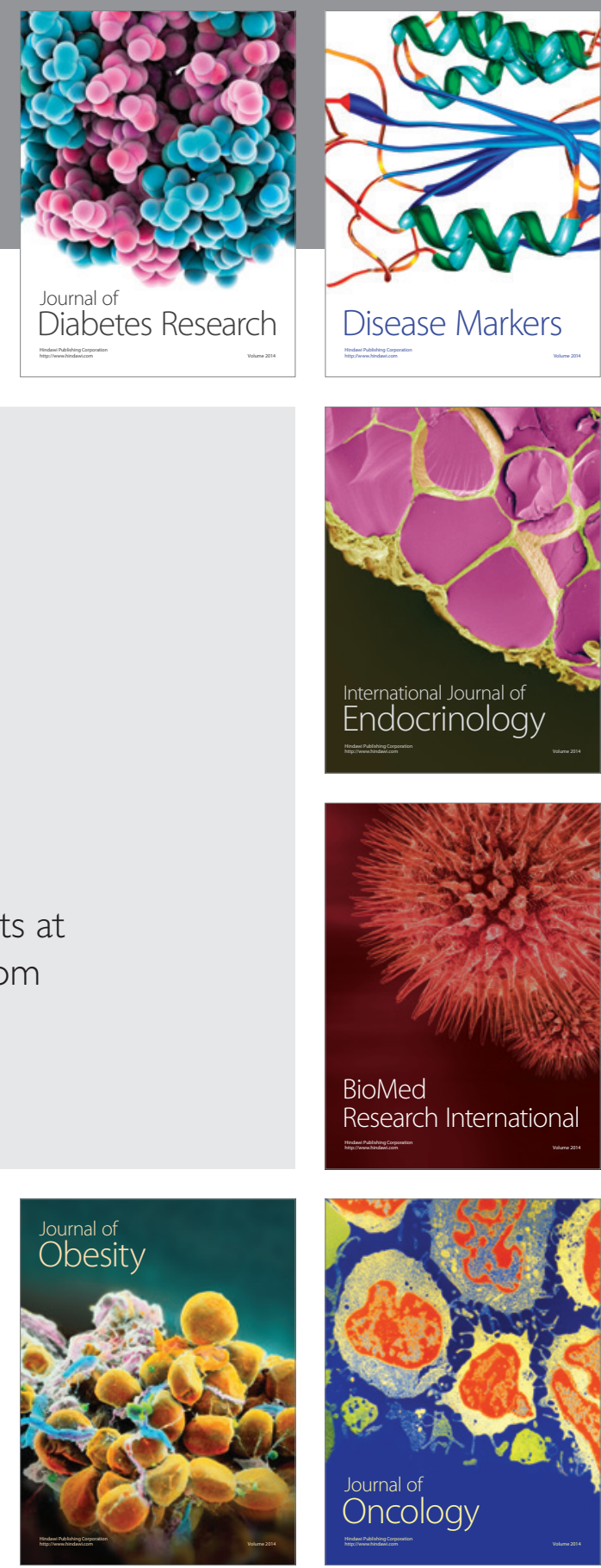

Disease Markers
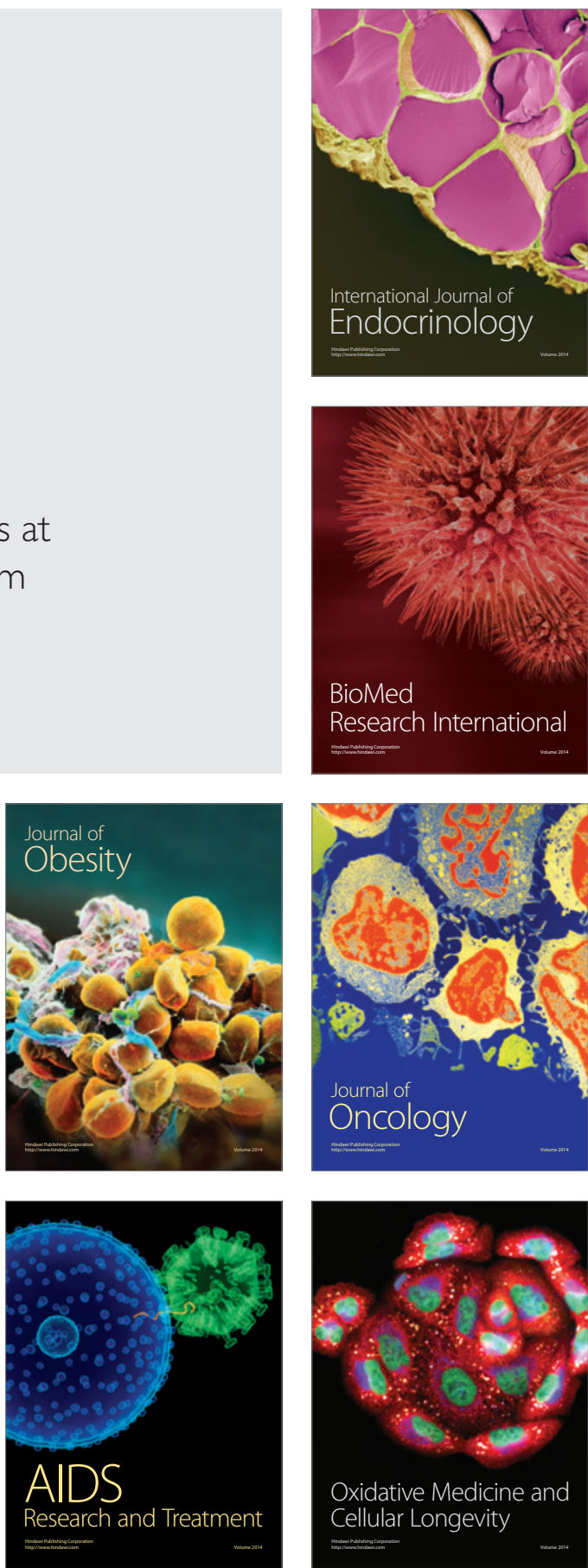